\title{
Liver resection for hepatocellular
} carcinoma within a fast-track management: a propensity-score matched analysis between open and laparoscopic approach

\author{
Francesca Ratti ${ }^{1}$, Federica Cipriani ${ }^{1}$, Raffaella Reineke ${ }^{2}$, Marco Catena ${ }^{1}$, Michele Paganelli ${ }^{1}$, Luigi Beretta ${ }^{2}$, Luca \\ Aldrighetti ${ }^{1}$
}

${ }^{1}$ Hepatobiliary Surgery Division, IRCCS San Raffaele Hospital, 20132 Milano, Italy.

${ }^{2}$ Department of Anaesthesiology and Intensive Care, IRCCS San Raffaele Hospital, 20132 Milano, Italy.

Correspondence to: Dr. Francesca Ratti, Hepatobiliary Surgery Division, IRCCS San Raffaele Hospital, Via Olgettina 60, 20132 Milano, Italy. E-mail: ratti.francesca@hsr.it

How to cite this article: Ratti F, Cipriani F, Reineke R, Catena M, Paganelli M, Beretta L, Aldrighetti L. Liver resection for hepatocellular carcinoma within a fast-track management: a propensity-score matched analysis between open and laparoscopic approach. Hepatoma Res 2016;2:271-8

Article history:

Received: 08-06-2016

Accepted: 20-09-2016

Published: 30-09-2016

Key words:

Hepatocellular carcinoma,

fast track,

laparoscopy,

liver surgery,

enhanced recovery after surgery,

liver failure

\begin{abstract}
Aim: The study was designed to assess the implications of enhanced recovery after surgery (ERAS) approach in patients submitted to open liver resection for hepatocellular carcinoma (HCC) comparing their short term outcome with patients treated by laparoscopic approach, in a case-matched design. Methods: The open-group $(n=60)$ was matched in a ratio of 1:1 with patients undergoing laparoscopic liver resection for HCC (Lap-group, $n=60$ ), with a matching achieved on a basis of propensity scores including 6 covariates representing patients characteristics and severity of the disease. Primary outcome analysis was performed in terms of ERAS-specific items and postoperative morbidity and mortality. Results: Overall morbidity and mortality were comparable between groups. Incidence of ascites was slightly higher in the open- compared with the Lap-group (respectively $11.7 \%$ and $13.3 \%$ ), without statistical significance. The need for introduction or increase of chronic diuretic therapy was significantly higher in the open-compared with the Lap-group $(16.7 \%$ vs. $11.7 \%, P=0.046)$. Furthermore, ascites more frequently required percutaneous drainage in the open-compared with the Lap-group ( $5 \%$ vs. $1.7 \%$ respectively, $P=0.041)$. Conclusion: In patients who can't benefit from minimally-invasive approach because of disease characteristics, ERAS management seems to be associated with an improved postoperative functional recovery and postoperative outcomes, comparable to those of the minimally invasive approach.
\end{abstract}

\section{INTRODUCTION}

Thanks to the widespread diffusion of laparoscopic surgery of the liver, surgical technique has experienced a significant improvement that was widen to encompass even patients management. ${ }^{[1-3]}$ Indeed, this innovative trend included the application of multimodal perioperative care protocols, called fast track or enhanced recovery

(i) (2) This is an open access article distributed under the terms of the Creative Commons Attribution-

EY NC SA NonCommercial-ShareAlike 3.0 License, which allows others to remix, tweak, and build upon the work non-commercially, as long as the author is credited and the new creations are licensed under the identical terms.

For reprints contact: service@oaepublish.com

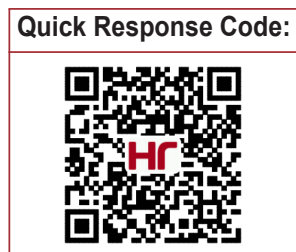


programmes (enhanced recovery after surgery, ERAS) which allowed to achieve a significant gain in terms of postoperative outcome in many abdominal surgical procedures. ${ }^{[4]}$ Many factors have a recognized impact on delayed postoperative recovery (pain, gut dysfunction and immobility): to reduce peri-operative stress and organ dysfunction, fast-track programmes were developed with the rationale of targeting these factors and with the aim of accelerating postoperative recovery and reduce length of stay, even lowering the rate of postoperative complications. ${ }^{[5]}$ Furthermore, it is reported that the establishment and adoption of evidence-based practice guidelines improves surgical outcomes: ${ }^{[6]}$ with this aim, a dedicated and specific program with well-defined recovery and discharge criteria was developed and applied into daily clinical practice of centres with a strong commitment in minimally-invasive approach. Thanks to encouraging results, many items of ERAS program have been more extensively implemented and their application was extended even to conventional open surgery. ${ }^{[7,8]}$

The preservation of wall portosystemic shunts is one of the advantages of laparoscopic approach when performed in patients with hepatocellular carcinoma (HCC), with a favourable impact on postoperative outcome leading to a reduced rate of hepatic decompensation. ${ }^{[9,10]}$ Many reports, including a metaanalysis from Zhou et al. ${ }^{[11]}$ concluded that laparoscopic liver resection (LLR) for HCC allows to obtain more favourable outcomes compared with open liver resection (OLR) in terms of its perioperative results, although it does not negatively affect the oncological outcomes. However, while most studies evaluating the results of LLR and OLR for HCC are retrospective series collected out of the fast-track perspective, ${ }^{[12]}$ patients affected by HCC, requiring liver resection but unsuitable for laparoscopy, might benefit from ERAS management since they have a baseline higher risk of postoperative complications due to peri-operative stress. To our knowledge, no specific report exists to prospectively evaluate this topic. The present study was designed to assess the implications of ERAS approach in patients submitted to open liver resection for HCC comparing their short term outcome with patients treated by laparoscopic approach, in a casematched design using propensity scores.

\section{METHODS}

\section{Study population}

In total 2,058 liver resections were performed at the Hepatobiliary Surgery Division of San Raffaele Hospital, Milano in the period between January 2004 and April 2016. Of these, $469(22.8 \%)$ were performed for HCC. Fast-track principles were systematically applied to LLR and in 2011 these principles were broadened to encompass even OLR. From 2012 on, a dedicated, "ERAS items-based" database was used to prospectively collect data from these procedures and to improve their reproducibility and comparability. During the study period (2012-2016), 203 resections for HCC were performed. Procedures with any of the following characteristics were identified and excluded: re-resections, need for associated vascular or biliary reconstruction, major vascular involvement or thrombosis, extra-hepatic disease. A group of 156 eligible resections was obtained. Among these, 81 had been operated on by an open approach.

With a ratio of $1: 1$ patients undergoing open liver resection were matched with those who had undergone LLR for HCC, to constitute the open-group ( $n=60$, study group) and the Lap-group, ( $n=60$, control group). Propensity scores were used to achieved the matching, with the following 6 covariates included: age, American Society of Anesthesiology score, Child-Pugh class, tumor size, nodularity, and extent of hepatectomy.

\section{Preoperative workup}

Liver function tests (to assess Child-Pugh classification) and serum tumor markers, abdominal ultrasonography, thoracoabdominal imaging were used as a standard preoperative assessment. Weekly multidisciplinary meetings, including liver surgeons, radiologists and medical oncologist were systematically performed, discussing patients who were potential candidates for LLR to define the final indication for the surgical procedure and both the type and the resection technique.

\section{Surgical technique}

A right subcostal extended to midline incision was performed in open cases. The "French" position was used to place patients submitted to laparoscopic resections, with the first surgeon standing between the patient's legs and one assistant on each side. A 4-trocar configuration was generally used with a $15 \mathrm{~mm}$ port to house the $30^{\circ}$ laparoscope. The SonoSurg system (Olympus, Tokyo, Japan) integrating both the ultrasonic coagulating cutter and the conventional ultrasonic dissector was used to perform the hepatic transaction. ${ }^{[13]}$ Pringle maneuver was used to control intraoperative bleeding.

\section{Perioperative management}

The ERAS multimodal protocol was adapted from the initial model to elective liver surgery, ${ }^{[7]}$ with the main goal to enhance functional recovery [Table 1]. A specific anaesthesiological management protocol was also developed to guide both intraoperative monitoring 
Table 1: Fast-track management protocol

\begin{tabular}{|c|c|}
\hline \multicolumn{2}{|l|}{ Before surgery } \\
\hline & $\begin{array}{l}\text { Preoperative counselling (surgeon, } \\
\text { anaesthesiologist, nurse) }\end{array}$ \\
\hline & Normal oral nutrition until midnight \\
\hline & No preanaesthetic medication \\
\hline & No bowel preparation \\
\hline \multicolumn{2}{|l|}{ Day of surgery } \\
\hline & Carbohydrate drinks up to $2 \mathrm{~h}$ before \\
\hline & $\begin{array}{l}\text { surgery } \\
\text { Local analgesia* }\end{array}$ \\
\hline & Short-acting i.v. anaesthetic agent \\
\hline & $\begin{array}{l}\text { Nasogastric drainage remove immediately } \\
\text { after surgery }\end{array}$ \\
\hline & Warm i.v. fluids and lower body air-warming \\
\hline & $\begin{array}{l}\text { Avoidance of excessive i.v. fluids } \\
\text { (intraoperative SVV }>12 \%)^{*}\end{array}$ \\
\hline & No routine drainage of the peritoneal cavity \\
\hline & $\begin{array}{l}\text { Allowed intake of water/nutrition after } \\
\text { surgery }\end{array}$ \\
\hline & Patient sent to surgical ward \\
\hline \multicolumn{2}{|c|}{ Postoperative day 1} \\
\hline & Patient mobilizes with physiotherapist \\
\hline & Patient drinks at least $1.5 \mathrm{~L}$ \\
\hline & Normal diet \\
\hline & Continue portable local analgesia \\
\hline & $1,000 \mathrm{mg}$ paracetamol every $8 \mathrm{~h}$ \\
\hline & Laboratory tests \\
\hline \multicolumn{2}{|c|}{ Postoperative day 2} \\
\hline & Continue portable local analgesia \\
\hline & Discontinuation of ev fluids \\
\hline & Remove urinary catheter \\
\hline & Continue mobilization \\
\hline & $1,000 \mathrm{mg}$ paracetamol every $8 \mathrm{~h}$ \\
\hline & Normal diet \\
\hline \multicolumn{2}{|c|}{ Postoperative day 3} \\
\hline & Start tapentadol \\
\hline & Stop local analgesia \\
\hline & Continue mobilization \\
\hline & Normal diet \\
\hline & Laboratory tests \\
\hline & Check discharge criteria \\
\hline \multicolumn{2}{|c|}{ Postoperative day 4} \\
\hline & Check discharge criteria \\
\hline & $\begin{array}{l}\text { Patient receives telephone number of case } \\
\text { manager nurse }\end{array}$ \\
\hline & Discharge \\
\hline \multicolumn{2}{|l|}{ Discharge criteria } \\
\hline & Adequate oral feeding \\
\hline & Adequate pain control with oral analgesics \\
\hline & $\begin{array}{l}\text { Normal deambulation and self-care } \\
\text { autonomy }\end{array}$ \\
\hline & No complications \\
\hline & Bowel recovery \\
\hline & Patient agreement \\
\hline
\end{tabular}

*See Table 2 for anaesthesiological management protocols. SVV: stroke volume variation

of patients volemic status and postoperative pain management [Table 2].

Definition of functional recovery was based on the following criteria (the patient is considered functional recovered when all the criteria are met):
Table 2: Intra- and postoperative management of volemic status and pain

\begin{tabular}{|c|c|c|c|}
\hline & Minor open & Major open & Laparoscopic \\
\hline CVC & No & No & No \\
\hline Vigileo & Yes & Yes & Yes \\
\hline Anaesthesia & $\begin{array}{c}\text { Gen + Peri or } \\
\text { Gen + Spin } \\
\text { \&TAP }\end{array}$ & Gen + PVT & $\begin{array}{c}\text { Gen }+ \text { Spin \& } \\
\text { TAP }\end{array}$ \\
\hline Paracetamol & $1 \mathrm{~g} \times 3$ & $1 \mathrm{~g} \times 3$ & $1 \mathrm{~g} \times 3$ \\
\hline Tapentadol & $\begin{array}{l}50 \mathrm{mg} \times 2 \text { (if } \\
\text { spinal) }\end{array}$ & $50 \mathrm{mg} \times 2$ & $50 \mathrm{mg} \times 2$ \\
\hline NSAID & $\begin{array}{c}\text { Ketorolac } 30 \\
\text { mg ab } \\
\text { (max } 90 \mathrm{mg} \\
\text { die) }\end{array}$ & $\begin{array}{c}\text { Ketorolac } 30 \\
\text { mg ab } \\
\text { (max } 90 \text { mg } \\
\text { die) }\end{array}$ & $\begin{array}{c}\text { Ketorolac } 30 \mathrm{mg} \\
\mathrm{ab} \\
\text { (max } 90 \mathrm{mg} \text { die) }\end{array}$ \\
\hline
\end{tabular}

CVC: central venous catheter; Gen: general; Peri: peridural; Spin spinal; TAP: transversus abdominis pain block; PVT: paravertebral; NSAID: nonsteroidal anti-inflammatory drug

(1) Pain adequately controlled with oral analgesics;

(2) Independently mobile (mobile at preoperative level);

(3) Tolerance of solid food: fluid and solid food intake is monitored and must be returned to normal tolerance level, i.e. when oral intake of water and normal food is resumed and continued for at least $24 \mathrm{~h}$. Since postoperative nausea and vomiting obviously influences the intake of fluid and solid food, a specific prophylaxis is always performed;

(4) Normal or decreasing serum bilirubin;

(5) No intravenous fluids.

\section{Outcome evaluation}

Data regarding general characteristics of patients and disease were recorded. Intraoperative and postoperative outcome were evaluated, including morbidity and mortality. Postoperative complications were reviewed for 90 days following liver resection and were graded according to Dindo-Clavien classification of surgical complications. ${ }^{[14]}$ Ascites was defined as an output $>500 \mathrm{~mL}$ per day from abdominal drainage (when positioned) or a clinically relevant abdominal distension requiring diuretics and/or iv albumin. Postoperative mortality was defined as any death during postoperative hospitalization or within 90 days after resection.

Specific issue regarding ERAS management (nasogastric tube and drainage placement, oral feeding, mobilization, bowel canalization, adequate pain control with oral analgesics, time for functional recovery, agreement for discharge, rate of readmission, length of stay) were specifically collected and analyzed.

\section{Statistical analysis}

Matching control patients undergoing laparoscopic surgery were selected according to propensity scores based on 6 covariates in a ratio of 1:1 with the opengroup: this study design was chosen to adjust for the 
Table 3: Preoperative characteristics of patients among groups

\begin{tabular}{|c|c|c|c|}
\hline Variables & Lap-group $(n=60)$ & Open-group $(n=60)$ & $P$ \\
\hline Age, mean $\pm \mathrm{SD}^{*}$ & $66 \pm 7$ & $69 \pm 6$ & NS \\
\hline Gender, M/F, $n(\%)$ & $35 / 25(58.3 / 41.7)$ & 29/31 (48.3/51.7) & NS \\
\hline ASA, $2 / 3, n(\%)^{*}$ & $31 / 29(51.6 / 48.4)$ & $31 / 29(51.6 / 48.4)$ & NS \\
\hline Comorbidities, $n(\%)$ & $36(60)$ & $38(63.3)$ & NS \\
\hline Underlying liver impairment, $n(\%)$ & & & NS \\
\hline Healthy liver & $10(16.7)$ & $10(16.6)$ & \\
\hline Mild impairment & $18(30)$ & $31(51.7)$ & \\
\hline Cirrhosis & 32 (53.3) & $19(31.7)$ & \\
\hline Child class, $n(\%)^{*}$ & & & NS \\
\hline A & 53 (88.3) & $57(95)$ & \\
\hline $\mathrm{B}$ & $7(11.7)$ & $3(5)$ & \\
\hline C & $0(0)$ & $0(0)$ & \\
\hline Tumor size, $\mathrm{cm}$, mean $\pm \mathrm{SD}^{*}$ & $3.6 \pm 1.2$ & $4.1 \pm 1.6$ & NS \\
\hline Tumor location, $n(\%)$ & & & 0.039 \\
\hline Laparoscopic Sg & $48(80)$ & $1(1.7)$ & \\
\hline Non laparoscopic Sg & $12(20)$ & $59(98.3)$ & \\
\hline Nodularity, $n(\%)^{*}$ & & & NS \\
\hline Single & $53(88.3)$ & $53(88.3)$ & \\
\hline Multiple & $7(11.6)$ & $7(11.6)$ & \\
\hline
\end{tabular}

${ }^{*}$ Covariate used for propensity score matching. M: male; F: female; ASA: American Society of Anesthesiology; Sg: segment; NS: not significant

different covariate distributions of the 2 groups. After matching, all variables were compared using the $X^{2}$ or Fisher's exact test for categorical data, the MannWhitney $\mathrm{U}$ test for non-normally distributed continuous data, and Student's t-test for normally distributed continuous variables. All data are expressed as mean plus or minus the standard deviation or median and range, as appropriate. Significance was defined as $P<$ 0.05 . All analyses were performed using the Statistical Package SPSS 18.0 (SPSS, Chicago, IL, USA).

\section{RESULTS}

\section{Patients and disease characteristics}

Patients and disease characteristics are summarized in Table 3. A minority of patients had impaired liver function, classified as Child B (respectively $11.7 \%$ in the Lap-group and $5 \%$ in the open-group). A different distribution of lesions within liver segments was recorded comparing the 2 groups: in particular lesions in the so called non-laparoscopic segments $(1,7,8)$ were $20 \%$ in the Lap-group and $98.3 \%$ in the opengroup $(P=0.039)$.

\section{Surgical procedures and intraoperative outcome}

The procedures are reported in details in Table 4. In particular, major hepatectomies were performed in $18.3 \%$ of patients in the Lap-group and in $15 \%$ of patients in the open-group. Mean intraoperative blood loss was higher in the open-compared with the Lapgroup (respectively $300 \pm 250 \mathrm{~mL}$ and $200 \pm 100$ $\mathrm{mL}$ ), even though this difference was not statistically significant. Thirteen point $3 \%$ of patients belonging to Lap-group required conversion to open approach: most frequent reasons for conversion were bleeding ( 3 patients) and oncological adequacy (5 patients). A R0 resection margin was obtained in 59 patients (98.3\%) in the Lap-group and 58 patients (96.7\%) in the opengroup, without significant differences.

Nasogastric tube was routinely removed after surgery in all the patients, following ERAS principles; only one patient with known swallowing disorder (in the open-group) had the tube removed in the second postoperative day. Patients who required surgical drainage were those with intraoperative evidence of bile leakage from the surface of the transected liver or with lesions located in areas unsuitable for an eventual percutaneous drainage (11 patients in the Lap-group and 13 patients in the open-group). Four patients in the Lap-group and 6 in the open-group underwent central venous catheter placement during surgery, while volemic status was intraoperatively monitored by the means of stroke volume variation measure.

\section{Postoperative outcome}

Table 5 reports postoperative outcome. Overall morbidity and mortality were comparable between groups. A detailed analysis of the rate of postoperative liver failure in terms of hepatic decompensation was performed: incidence of ascites was slightly higher in the opencompared with the Lap-group (respectively 11.7\% and $13.3 \%$ ), without statistical significance. Despite this, the need for introduction or increase of chronic diuretic therapy (both for ascites or peripheral edema) was significantly higher in the open- compared with the Lap-group ( $16.7 \%$ vs. $11.7 \%, P=0.046)$. Furthermore, ascites more frequently required percutaneous drainage in the open- compared with the Lap-group (5\% vs. 
Table 4: Intraoperative outcome among groups

\begin{tabular}{|c|c|c|c|}
\hline Variables & Lap-group $(n=60)$ & Open-group $(n=60)$ & $P$ \\
\hline Procedure, $n(\%)$ & & & NS \\
\hline Wedge resection & $19(31.7)$ & $16(26.7)$ & \\
\hline Segmentectomy & $16(26.7)$ & $21(35.0)$ & \\
\hline Left lateral sectionectomy & $8(13.3)$ & $3(5)$ & \\
\hline Bisegmentectomy & $6(10)$ & $11(18.3)$ & \\
\hline Right hepatectomy & $5(8.3)$ & 5 (8.3) & \\
\hline Left hepatectomy & $6(10)$ & $4(6.7)$ & \\
\hline Resection extent, $n(\%)^{*}$ & & & NS \\
\hline Minor & $49(81.7)$ & $51(85)$ & \\
\hline Major & $11(18.3)$ & $9(15.0)$ & \\
\hline Associated procedures, $n(\%)$ & & & NS \\
\hline Cholecistectomy & $31(51.7)$ & $33(55)$ & \\
\hline RF ablation & $4(6.7)$ & $3(5)$ & \\
\hline Operative time, min, mean \pm SD & $190 \pm 55$ & $140 \pm 45$ & NS \\
\hline Blood loss, $\mathrm{mL}$, mean $\pm \mathrm{SD}$ & $200 \pm 100$ & $300 \pm 250$ & NS \\
\hline Conversion to laparotomy, $n(\%)$ & $8(13.3)$ & NA & \\
\hline Pringle maneuver, $n(\%)$ & $50(83.3)$ & $48(80)$ & NS \\
\hline \multicolumn{4}{|l|}{ Resection margin, $n(\%)$} \\
\hline Ro & $59(98.3)$ & $58(96.7)$ & NS \\
\hline $\mathrm{R} 1$ & $1(1.7)$ & $2(3.3)$ & NS \\
\hline Total PRBC transfusion, $n(\%)$ & $6(10)$ & $7(11.7)$ & NS \\
\hline Nasogastric tube removed in OR, $n(\%)$ & $60(100)$ & $59(98.3)$ & NS \\
\hline Drainage placement, $n(\%)$ & $11(18.3)$ & $13(21.7)$ & NS \\
\hline CVC placement, $n(\%)$ & $4(6.7)$ & $6(10)$ & \\
\hline Epidural/paravertebral analgesia, $n(\%)$ & $52(86.7)$ & $51(85)$ & NS \\
\hline Need for ICU, $n(\%)$ & $1(1.7)$ & $1(1.7)$ & NS \\
\hline
\end{tabular}

${ }^{*}$ Covariate used for propensity score matching. PRBC: packed red blood cells; OR: operating room; ICU: intensive care unit; RF: radiofrequency; CVC: central venous catheter; NA: not available; NS: not significant

Table 5: Postoperative outcome among groups

\begin{tabular}{lccc}
\hline Variables & $\begin{array}{c}\text { Lap-group } \\
(n=60)\end{array}$ & $\begin{array}{c}\text { Open-group } \\
(\boldsymbol{n}=60)\end{array}$ & $\boldsymbol{P}$ \\
\hline Postoperative mortality, $n(\%)$ & $0(0)$ & $0(0)$ & NS \\
Postoperative morbidity, $n(\%)$ & $9(15)$ & $10(16.7)$ & NS \\
$\quad$ Minor (grade I-II) & $6(10)$ & $8(13.3)$ & NS \\
$\quad$ Major (grade III-V) & $3(5)$ & $2(3.3)$ & NS \\
Postoperative liver failure, $n(\%)$ & $1(1.7)$ & $2(3.3)$ & NS \\
Ascites, $n$ (\%) & $7(11.7)$ & $8(13.3)$ & NS \\
Hemorrage, $n(\%)$ & $1(1.7)$ & $1(1.7)$ & NS \\
Biliary fistula, $n(\%)$ & $1(1.7)$ & $2(3.3)$ & NS \\
Pleural effusion, $n(\%)$ & $2(3.3)$ & $5(8.3)$ & NS \\
Oral feeding, median (range) & $1(0-1)$ & $1(0-2)$ & NS \\
Mobilization, median (range) & $1(1-2)$ & $1(1-3)$ & NS \\
$\begin{array}{l}\text { Bowel canalization, median } \\
\text { (range) }\end{array}$ & $2(1-4)$ & $3(2-5)$ & NS \\
$\begin{array}{l}\text { Adequate pain control orally, } \\
\text { median (range) }\end{array}$ & $3(2-4)$ & $4(2-5)$ & NS \\
Time for functional recovery, & $3(2-5)$ & $3(3-5)$ & NS \\
median (range) & & & \\
$\begin{array}{l}\text { Agreement for discharge, } \\
\text { median (range) }\end{array}$ & $3(2-8)$ & $4(3-6)$ & NS \\
Hospital stay, median (range) & $4(3-9)$ & $5(4-10)$ & NS \\
Rate of readmission, $n$ (\%) & $2(3.3)$ & $3(5)$ & NS \\
\hline
\end{tabular}

NS: not significant

$1.7 \%, P=0.041)$ and finally, in patients who required intraoperative placement of the surgical drainage, daily output was higher in the open compared with the Lap- group (respectively $1,000 \pm 200 \mathrm{~mL}$ and $600 \pm 100 \mathrm{~mL}$, $P=0.05$ ), so that the drainage was left in place longer. The analysis of the series after exclusion of converted patients confirmed the same findings.

Overall, median length of postoperative stay was comparable between groups, being respectively 4 days (range: 3-9 days) in the Lap-group and 5 days (range: 4-10 days) in the open-group. Median time for functional recovery was 3 days in the Lap-, as well as in the open-group. The rate of readmission was 3.3\% in the Lap-group (2 patients were re-admitted: 1 due to fever and 1 for refractory ascites) and $5 \%$ in the opengroup ( 3 patients: 1 biliary fistula, 1 pleural effusion and 1 fever).

\section{DISCUSSION}

Liver surgery for $\mathrm{HCC}$, in patients managed within a fast-track approach, seems to be feasible and safe both when performed by minimally-invasive and by open approach. This is, to our knowledge, the first series that compares the two techniques in an ERAS perspective, specifically in patients with HCC, for which laparoscopic approach was proved to be associated with improved outcomes in terms of intraoperative bleeding and postoperative complications. Outside 
of randomization, a case match design was chosen as the most suitable to address this bias of a possibly higher severity of disease or of a different liver function in laparoscopic patients.

The present study reports how the application of fasttrack management in the field of liver surgery for HCC allows to improve the results of open approach and to obtain a short term outcome similar to that of the laparoscopic technique. Despite this, laparoscopy confirms its advantage, as already reported in most series and meta-analyses available until now in the literature. ${ }^{[9-12]}$ Indeed, in spite of a comparable incidence of postoperative hepatic decompensation (ascites) between the Lap- and the open-group, patients in the open-group more frequently required the introduction or the increase of diuretic therapy in the period after surgery. In cirrhotic patients indeed, the advantages of laparoscopy include the preservation of wall portosystemic shunts and the round ligament, consequently no increases in portal pressure are recorder: this is the physiopathological basis for the increased risk of bleeding and ascites. ${ }^{[9,11,12]}$ Moreover, the impact of laparoscopy on postoperative outcome, due to negative effects related to inflammatory profile and coagulation homeostasis alterations, are reduced compared to conventional surgery, ${ }^{[9]}$ thanks to the conceptual change in perioperative management protocols, that was recently applied even in open surgery. Factors that delay postoperative recovery (pain, gut dysfunction and immobility) were targeted, resulting in a reduction of the peri-operative stress and organ dysfunction.

As widely reported in the literature ${ }^{[4-8]}$ ERAS approach is based on several different items, with a different range of penetration and application among centers implementing fast-track programs. Furthermore, WongLun-Hing et al. ${ }^{[8]}$ demonstrated that the advantage associated with this perioperative management significantly correlates with compliance with the ERAS program, so that there is further need to further optimize the ERAS strategy within a multidisciplinary effort. In our center, the implementation of fast-track was wide since the beginning of the experience: then, after the first period of application, the protocol was revised by the multidisciplinary team to allow the use of a protocol tailored on the characteristics of both the institution and the series. Due to the relatively statistically limited power of a comparison between the first and the subsequent experience related to a still reduced pool of patients, the effective improvement of results along with the reappraisal of the protocol was not analyzed in the present series and was beyond study aims.
The figure of the "case-manager nurse" was introduced with the aim of being a contact-person during patients hospital stay and to monitor the early period following discharge: indeed, thanks to the frequent contact, the family and the patient himself have the feeling of a "protected-discharge" regimen and any complication occurring at home is not misinterpreted or misdiagnosed. This even allows to lower the rate of unnecessary or inappropriate accesses in the Emergency Department.

The issue of the impact of prophylactic drainage in patients with underlying liver impairment was analysed in a specifically designed randomized controlled trial, ${ }^{[15]}$ which reported a detrimental effect of abdominal drainage on morbidity, without really be adequate in detection of bile leakages and bleedings. A meta-analysis by Petrowsky et al., ${ }^{[16]}$ including all randomized trials ${ }^{[15,17,18]}$ focused on the issue of drainages in liver surgery, concluded that there is a slight outcome advantage for nondrained patients. While in our first experience, the abdominal drainage was systematically avoided both in the laparoscopic and in the open approach. In the current clinical practice we recommend the avoidance of drainage unless there is any concern in terms of biliostasis or if the transection surface can't be easily drained by the means of an eventual percutaneous approach. Indeed, the avoidance of postoperative drainage as prescribed by ERAS protocols (unless necessary to specifically monitor the risk of biliary fistula), may confer an advantage to patients with impaired liver function.

The role of intraoperative volemic control was a flagship issue in the ERAS protocol: indeed, maintenance of patient's hypovolemia and avoidance of water overload seem to favourably affect the intraoperative outcome of candidates to hepatic resection reducing blood loss and transfusion rate. ${ }^{[19,20]}$ In laparoscopic liver surgery, the positive effect of hypovolemia is increased since it allows to reduce bleeding from hepatic veins: indeed, this kind of bleeding can't be controlled by portal triad clamping and it is frequently responsible for conversion to open approach. ${ }^{[21,22]}$ Cardiac preload has been traditionally monitored by central venous pressure, while recently, haemodynamic changes during surgery have been successfully assessed using minimally-invasive devices like Flotrac/Vigileo that is proved to be safe and reliable. ${ }^{[23]}$ Since in cirrhotics baseline systemic vascular resistance is lower and less sensitive to hemodynamic changes, these patients have altered capability to respond to portal clamping so that intraoperative administration of vasopressors (norepinephrine and dopamine) might be required. Crystalloid administration was generally suspended 
the second day after surgery unless specifically required by clinical conditions of the patient. In the setting of patients with liver impairment, total body water expansion and renal sodium retention may lead to excessive loss of water across the splanchnic capillaries into the peritoneum, causing expansion of extravascular compartment, worsening ascites decompensation and contributing to hyperdynamic circulatory syndrome. ${ }^{[24]}$ In patients with clinically evident ascites and without drainage, paracentesis is usually not recommended, while administration of albumin and diuretics has to be preferred (unless ascites infection is suspected). ${ }^{[25]}$

The task of faster postoperative functional recovery could be addressed even thanks to a better management of postoperative pain allowing earlier mobilization and return to a good quality of life. In patients with cirrhosis and alterations of coagulation profile and platelet count, placement of epidural catheter (recommended in fast track programs) should be avoided, ${ }^{[26]}$ right paravertebral thoracic block $^{[27]}$ and spinal block ${ }^{[28]}$ are available alternatives, allowing to avoid side effects of oppioids.

In conclusion, in patients who can't benefit from minimally-invasive approach because of disease characteristics (i.e. tumor location within the liver), ERAS management seems to be associated with an improved postoperative functional recovery and postoperative outcomes comparable to those of the minimally-invasive approach. So, any further effort to optimize and implement fast-track programs in the daily clinical practice for these patients has to be strongly recommended.

\section{Financial support and sponsorship} None.

\section{Conflicts of interest}

There are no conflicts of interest.

\section{Patient consent}

Consents from subjects were waived.

\section{Ethics approval}

Approved by the internal review board of IRCCS San Raffaele Hospital.

\section{REFERENCES}

1. Nguyen KT, Gamblin TC, Geller DA. World review of laparoscopic liver resection-2,804 patients. Ann Surg 2009:250:831-41.

2. Buell JF, Cherqui D, Geller DA, O'Rourke N, Iannitti D, Dagher I, Koffron AJ, Thomas M, Gayet B, Han HS, Wakabayashi G, Belli G, Kaneko H, Ker CG, Scatton O, Laurent A, Abdalla EK, Chaudhury P,
Dutson E, Gamblin C, D’Angelica M, Nagorney D, Testa G, Labow D, Manas D, Poon RT, Nelson H, Martin R, Clary B, Pinson WC, Martinie J, Vauthey JN, Goldstein R, Roayaie S, Barlet D, Espat J, Abecassis M, Rees M, Fong Y, McMasters KM, Broelsch C, Busuttil R, Belghiti J, Strasberg S, Chari RS; World Consensus Conference on Laparoscopic Surgery. The international position on laparoscopic liver surgery: the Louisville Statement, 2008. Ann Surg 2009;250:825-30.

3. Pulitanò C, Aldrighetti L. The current role of laparoscopic liver resection for the treatment of liver tumors. Nat Clin Pract Gastroenterol Hepatol 2008;5:648-54.

4. Kehlet H, Wilmore DW. Multimodal strategies to improve surgica outcome. Am J Surg 2002;183:630-41.

5. Stoot JH, van Dam RM, Busch OR, van Hillegersberg R, De Boer M, Olde Damink SW, Bemelmans MH, Dejong CH; Enhanced Recovery After Surgery (ERAS) Group. The effect of a multimodal fast-track programme on outcomes in laparoscopic liver surgery: a multicentre pilot study. HPB (Oxford) 2009;11:140-4.

6. Chun J, Bafford AC. History and background of quality measurement. Clini Colon Rectal Surg 2014;27:5-9.

7. van Dam RM, Hendry PO, Coolsen MM, Bemelmans MH, Lassen K Revhaug A, Fearon KC, Garden OJ, Dejong CH; Enhanced Recovery After Surgery (ERAS) Group. Initial experience with a multimodal enhanced recovery programme in patients undergoing liver resection. Br J Surg 2008;95:969-75.

8. Wong-Lun-Hing EM, van Dam RM, Heijnen LA, Busch OR, Terkivatan T, van Hillegersberg R, Slooter GD, Klaase J, de Wilt JH, Bosscha K, Neumann UP, Topal B, Aldrighetti LA, Dejong CH. Is current perioperative prectice in hepatic surgery based on enhaced recovery after surgery (ERAS) principles? World J Surg 2014;38:1127-40.

9. Aldrighetti L, Guzzetti E, Pulitanò C, Cipriani F, Catena M, Paganelli M, Ferla G. Case-matched analysis of totally laparoscopic versus open liver resection for HCC: short and middle term results. J Surg Oncol 2010;102:82-6.

10. Wakabayashi G, Cherqui D, Geller DA, Buell JF, Kaneko H, Han HS, Asbun H, O’Rourke N, Tanabe M, Koffron AJ, Tsung A, Soubrane O, Machado MA,Gayet B, Troisi RI, Pessaux P, Van Dam RM, Scatton O, Abu Hilal M, Belli G, Kwon CH, Edwin B, Choi GH, Aldrighetti LA, Cai X, Cleary S, Chen KH, Schön MR, Sugioka A, Tang CN, Herman P, Pekolj J, Chen XP, Dagher I, Jarnagin W, Yamamoto M, Strong R, Jagannath P, Lo CM, Clavien PA, Kokudo N, Barkun J, Strasberg SM. Recommendations for laparoscopic liver resection: a report from the second international consensus conference held in morioka. Ann Surg 2015;261:619-29.

11. Zhou YM, Shao WY, Zhao YF, Xu DH, Li B. Meta-analysis of laparoscopic versus open resection for hepatocellular carcinoma. Dig Dis Sci 2011; 56(7):1937-43.

12. Yin Z, Fan X, Ye H, Yin D, Wang J. Short- and long-term outcomes after laparoscopic and open hepatectomy for hepatocellular carcinoma: a global systematic review and meta-analysis. Ann Surg Oncol 2013;20:1203-15.

13. Aldrighetti L, Pulitanò C, Arru M, Catena M, Guzzetti E, Casati M, Ferla G. Ultrasonic-mediated laparoscopic liver transection. Am J Surg 2008;195:270-2

14. Dindo D, Demartines N, Clavien PA. Classification of surgical complications: a new proposal with evaluation in a cohort of 6,336 patients and results of a survey. Ann Surg 2004;240:205-13.

15. Liu CL, Fan ST, Lo CM, Wong Y, Ng IO, Lam CM, Poon RT, Wong J. Adbominal drainage after hepatic resections is contraindicated in patients with chronic liver disease. Ann Surg 2004; 239:194-201.

16. Petrowsky H, Demartines N, Rousson V, Clavien PA. Evidence based value of prophylactic drainage in gastrointestinal surgery. A systematic review and meta-analyses. Ann Surg 2004;240:1074-85.

17. Fong Y, Brennan MF, Brown K, Heffernan N, Blumgart LH. Drainage is unnecessary after elective hepatic resection. Am J Surg 1996;171:158-62. 
18. Belghiti J, Kabbej M, Sauvanet A, Vilgrain V, Panis Y, Fekete F. Drainage after elective hepatic resection. A randomized trial. Ann Surg 1993;218:748-53.

19. Jones RM, Moulton CE, Hardy KJ. Central venous pressure and its effect onblood loss during liver resection. Br J Surg 1998;85:1058-60.

20. Feltracco P, Biancofiore G, Ori C, Saner FH, Della Rocca G. Limits and pitfalls of haemodynamic monitoring systems in liver transplantation surgery. Minerva Anestesiol 2012;78:1372-84.

21. Pulitanò C, Catena M, Arru M, Guzzetti E, Comotti L, Ferla G, Aldrighetti L. Laparoscopic liver resection without portal clamping: a prospective evaluation. Surg Endosc 2008;22:2196-200.

22. Cauchy F, Fuks D, Nomi T, Schwarz L, Barbier L, Dokmak S, Scatton O, Belghiti J, Soubrane O, Gayet B. Risk factors and consequences of conversion in laparoscopic major liver resection. $\mathrm{Br} J$ Surg 2015;102:785-95.

23. Ratti F, Cipriani F, Reineke R, Catena M, Paganelli M, Comotti L,
Beretta L, Aldrighetti L. Intraoperative monitoring of stroke volume variation versus central venous pressure in laparoscopic liver surgery: a randomized prospective comparative trial. HPB (Oxford) 2016;18:136-44.

24. Polli F, Gattinoni L. Balancing volume resuscitation and ascites management in cirrhosis. Curr Opin Anesthesiol 2010;23:151-8.

25. Jin S, Fu Q, Wuyun G, Wuyun T. Management of post-hepatectomy complications. World J Gastroenterol 2013;19:7983-91.

26. Matot I, Scheinin O, Eid A, Jurim O. Epidural anesthesia and analgesia in liver resection. Anesth Analg 2002;95:1179-71.

27. Ho AM, Karmakar MK, Cheung M, Lam GC. Right thoracic paravertebral analgesia for hepatectomy. Br J Anaesth 2004;93:458-61.

28. De Pietri L, Siniscalchi A, Reggiani A, Masetti M, Begliomini B, Gazzi M, Gerunda GE, Pasetto A. The use of intrathecal morphine for postoperative pain relief after liver resection: comparison with epidural analgesia. Anesth Analg 2006;102:1157-63. 